\title{
Technical readiness of young basketball players with different profile of functional asymmetry
}

\author{
Frolova L.S. ${ }^{\mathrm{ABCDE}}$, Petrenko Yu.O. ${ }^{\mathrm{AD}}$, Tymofeev A.A. ${ }^{\mathrm{BCD}}$, Gunko P.M. ${ }^{\mathrm{BC}}$, Okhrimenko O.V. ${ }^{\mathrm{BC}}$, Khaliavka R.M. ${ }^{\mathrm{BE}}$ \\ The Bohdan Khmelnytsky National University of Cherkasy, Ukraine
}

Authors' Contribution: A - Study design; B - Data collection; C - Statistical analysis; D - Manuscript Preparation; E - Funds Collection

\begin{abstract}
Purpose: $\quad$ The functional asymmetry is considered to be the basis of psycho physiological individual features of young basketball players. It indicates the dominant hemisphere while processing information concerning the precision in body movement in basketball playing technique. The research concerning the cerebral hemispheres asymmetry influence on the movement technique formation of young basketball players is still highly inconsistent. Therefore, the study aims at the determining technical readiness peculiarities of basketball players aged 12-13 with different cerebral asymmetry profiles while performing exercises with dominant and sub-dominant hands.

Material: $\quad 35$ basketball players aged 12-13 have been tested in order to determine the type of cerebral asymmetry and technical readiness. To determine the cerebral asymmetry, the computer modified test of Stroop was used. In order to define technical readiness, three exercises which are performed using the right and left hand have been developed.

Results: $\quad$ Half of the group of basketball players aged 12-13 do not have a clear lateralization of the hemispheres: $51 \%$ of participants have symmetry of the hemispheres, $28 \%$ - the functional activity of the right hemisphere, and $20 \%$ - the left hemisphere activity. The study showed that shots of basketball players with the left cerebral lateralization are more accurate when performed with dominant hand. They prevail in the speed and accuracy parameters of passing and dribbling with both hands as well.

Conclusions: The many-sided nature of the interhemispheric asymmetry of basketball players aged 12-13 was determined. Its influence on technical readiness was found out. The highest level of technical readiness has been found among basketball players with the left hemisphere dominance. The lowest level of technical readiness was recorded among basketball players with the right hemisphere dominance. It was specified, that at the age of $12-13$, the bimanual character of movements of young basketball players with left hemisphere dominance is being formed more actively.

Keywords: basketball, dominant and sub-dominant hand, ambidextrous character of body movements, interhemispheric correlation, direction and degree of lateralization.
\end{abstract}

\section{Introduction}

Morphologically, a person's body is considered to be relatively symmetrical, but the activity of paired organs has a set of differences that determines their functional asymmetry [1]. The problem of human functional asymmetry, especially cerebral asymmetry is difficult and has not been studied substantially. For many decades, the researches of scientists in various scientific fields have been devoted to this problem, being based on controversial concepts of the functional asymmetry formation during ontogenesis $[2,3]$.

From one point of view, the initial balance between the cerebral hemispheres is recognized concerning all functions [3], and on the other - genetically programmed specialization of the hemispheres is acknowledged [1, 4]. It is believed that the genotype controls the degree of asymmetry manifestation [2]. The data available, concerning the direction and the degree influence on functional asymmetry of human activity does not allow determining the optimal profile of lateral brain organization in various spheres, including sports [3, 5].

In order to ensure the reliable motor actions, an athlete should have both interhemispheric correlation [6]

(c) Frolova L.S., Petrenko Yu.O., Tymofeev A.A., Gunko P.M., Okhrimenko O.V., Khaliavka R.M., 2019

doi:10.15561/18189172.2019.0304 and their functional asymmetry [7, 8], which have been predetermined by genetic mechanisms [3]. However, it is believed that sports session can affect the direction and degree of morphological and functional asymmetry [5, 9].

In addition, taking into account the symmetryasymmetry factor during the training session control, especially of young athletes, allows us to determine the reserves of the style formation of their competitive activity $[7,10.11]$. This is important in the prospects for top scores.

The experimental results of functional asymmetry characterize the motor, sensory and psychic characteristics of athletes' asymmetry, taking into account the dominance of a particular organ, or its absence. Most studies are carried out in order to determine the asymmetry profile and its impact on various aspects of athletes' readiness. Therefore, it makes possible to emphasize the works that indicate the possibility of athletes' cognitive functions manifestation, depending on the hemisphere dominance $[12,13]$. The works, in which the dependence of the asymmetry individual profile on sports specialization, which affects the competitive result have been proved, are also of great importance $[7,11,14]$. The interaction between the nerve processes balance and the athletes' functional asymmetry [15] is investigated. 
In order to deal with an issue of athletes' individual differences in the context of functional asymmetry it is necessary to include the characteristics reflection of representatives of various sports, including basketball.

Contemporary researches on basketball players activity is being carried out in different directions: the features of morphological asymmetry are studied [10]; the dominance of the body parts is being determined $[5,16]$; the lateralization dependency factor on the experience and features of the training process is being defined [17-20]. All lines of the research are of great scientific interest, since they identify aspects of athletes' training session being optimized at different stages of preparation. However, there are some problems with the technique training of young basketball players, concerning the psycho-physiological individual features that have not been studied sufficiently. This fact served as a motive to find ways to solve these problems.

Purpose: to define the peculiarities of the technical readiness of basketball players aged 12-13 with a different cerebral asymmetry profile while exercise performing with dominant and sub-dominant hands.

\section{Materials \& methods}

\section{Participants}

The participants of the study were 35 basketball players (aged 12-13) of the "Cherkaski Mavpy" basketball club (Ukraine). All of them had basketball training experience for at least 4 years. In Ukraine, basketball players of this age are trained at the stage of preliminary basic training, the main task of which is to assess the skills prospects development which is considered to be important in basketball playing. The exact age of the participants was determined according to the data provided by the coach. The participants were informed about the purpose of the study, as well as about the risks and benefits. Since the participants were minors, the consent form to voluntary participation has been signed by coaches - their legal representatives.

\section{Instruments}

Technical readiness testing:

- ball passes with the right and left hands in pairs. Two players are at a distance of 3-4 meters from each other, everyone has a ball. By a signal, basketball players start passing the ball simultaneously with a right hand during 30 seconds. They catch the ball with both hands. The same is for the left hand;

- dribbling with the right and left hands. By a signal the basketball player starts dribbling with his right hand at a distance of 15 meters then turns around the cone at a distance of 7.5 meters from the start. The same is for the left hand;

- integrated drill. Five cones are placed around the 3 -second area perimeter. By a signal, the basketball player starts running from under the blackboard to the left, dribbling with his left hand, dribbling around the first cone and then makes a shot on the run with his left hand. Similarly, the athlete dribbles around the $2 \mathrm{~d}, 3 \mathrm{~d}, 4^{\text {th }}$ and $5^{\text {th }}$ cones with a subsequent shot after dribbling. The same is for the right hand, while running from under the blackboard to the right, to the 1 st cone.

The cerebral hemispheres asymmetry determination

The modified computer test of Stroop was applied [12]. In the centre of the computer screen the word signals "BLACK" and "GREEN" are being presented to the subject. Each word may be written in red or green.

Somewhat earlier, below the signal word, one of the words "SENSE" or "COLOR" written in a neutral colour (conditional feature) is being represented. These words determined the way of responding. The subject's task is to respond to signals according to the conditional feature, by pressing the right key in response to the "red" signal, and the left key in response to the "green" one. The "SENS" conditional feature, characterized by the red signal is the word "RED", regardless of the letters colour. The "COLOR" conditional feature, characterized by a word written in red letters is considered to be the red signal regardless of the content. The test consists of 64 signals, execution time is 1,5-3,0 minutes.

\section{Analysis of technical readiness data}

While passing the ball to a teammate, a number of accurate passes was being recorded (without giveaways). While dribbling, the passing time through the distance (without giveaways) was recorded with an accuracy of 0.1 second. During the integrated drill performance, the time from the start to its completion was recorded with an accuracy of 0.1 second, as well as the number of shots. The testing data has been recorded and the indicators have been divided taking into account the exercise performance with dominant and sub-dominant hands.

Analysis of testing data

The asymmetry index without the dominant pole as well as the index of the left-hemisphere dominance was calculated. The low asymmetry indexes are considered to be a sign of symmetry, whereas high indicators are a sign of asymmetry. The low index values of the lefthemisphere dominance indicate the dominance of the right hemisphere; high values indicate the left hemisphere dominance.

\section{Procedure}

The study was conducted in September-November 2017. The participants were tested in the allotted time. The testing procedure of technical readiness has been carried out for 12 weeks on a standard basketball court. Each test on the right and left hands drill performance was carried out once a week in the presence of all the basketball players of the group. Computer testing took place on a day off once a week. The health condition of all basketball players at the time of the research was satisfactory.

\section{Statistical analysis}

All received experimental data was processed using Microsoft Excel. Descriptive statistics has been performed using an average and standard deviation. The significance level equals 0.05 . Correlation or relationship between the two values was established by logical reasoning. By applying correlation analysis, the relation degree as well as its character was determined. 


\section{Results}

Functional asymmetry analysis has shown that half of the group of basketball players aged 12-13 do not have defined hemispheres lateralization. In 51\% (18 persons) of the athletes examined, the hemispheres symmetry was detected, $28 \%$ of the athletes (10 persons) had the tendencies to the functional activity of the right hemisphere, and in $20 \%$ ( 7 persons) the functional activity of the left hemisphere was recorded.

It should be noted, that among 35 basketball players under study, 14\% (5 persons) have the left hemisphere dominance, while $86 \%$ (21 persons) have the right one. Among the young basketball players with the left hemisphere dominance, 2 persons with hemispheric symmetry, 2 persons with left-sided cerebral lateralization and 1 person with right-sided cerebral lateralization were diagnosed.

The data on the technical readiness of basketball players have been presented in accordance with the distribution of the cerebral functional asymmetry profile. In this case, the data characteristics of the profiles specified have been performed taking into account the exercise performance with the right and left hands without specifying the motor asymmetry direction.

It allowed us to consider exercising indicators with dominant and sub-dominant hands. The technical readiness study on exercise performance with dominant hand found significant differences between groups of basketball players with different cerebral asymmetry profiles (Table 1).

Basketball players with the right hemisphere dominance had lower indicators in ball passing, compared to the athletes' results with the left hemisphere dominance $(p<0.05)$. The indicators difference is 6.33 times $(p<0.05)$. But no significant differences were found between groups with asymmetry and group with interhemispheric correlation ( $\mathrm{p}>0.05)$.

The highest shot accuracy was demonstrated by basketball players with the left hemisphere dominance. The difference between groups with different direction of asymmetry is 1.06 times $(p<0.05)$. The difference in shot accuracy between the groups with the left hemisphere dominance and symmetry is 0.75 times $(p<0.05)$.
No significant differences in the rates of integrated drill performance were found between groups with different cerebral asymmetry profiles $(\mathrm{p}<0.05)$.

The best dribbling result was demonstrated by the basketball players with the left hemisphere dominance. The indicators difference in the groups with different activity of the hemispheres was $0.29 \mathrm{~s}(\mathrm{p}<0.05)$. The dribbling indicators difference between the groups with the left hemisphere dominance and symmetry was 0.09 $\mathrm{s} \quad(\mathrm{p}<0.05)$. Basketball players with the hemisphere symmetry demonstrated higher dribbling results, than the athletes with the right hemisphere dominance (at $0.2 \mathrm{~s}$; $\mathrm{p}<0.05)$.

The study of technical readiness during drill performance with the sub-dominant hand has also showed the difference between groups of basketball players with different cerebral profile asymmetry (Table 2).

The best time during integrated drill performance was demonstrated by basketball players with hemisphere symmetry and left hemisphere dominance, as compared to the right hemisphere one. The difference was 1.47 $\mathrm{s}(\mathrm{p}<0.05)$ and $0.6 \mathrm{~s}(\mathrm{p}<0.05)$ accordingly. The shots accuracy in groups with different cerebral asymmetry profiles was almost identical $(\mathrm{p}>0.05)$. The top dribbling result was showed by the basketball players in the group with the left hemisphere dominance. The difference, compared with the indicators of basketball players with the right hemisphere profile was $0.41 \quad(p>0.05)$ and compared with the indicators of basketball players with the hemispheres symmetry was $0.28 \mathrm{~s}(\mathrm{p}>0.05)$.

The top passing result was demonstrated by basketball players with the left hemisphere dominance $(p<0.05)$. Basketball players with hemispheres symmetry showed a lower result $(5.71$ times) $(\mathrm{p}<0.05)$. Basketball players with the right hemisphere activity demonstrated the lowest rates, different from the other two groups $(p<0.05)$.

The correlation analysis of technical readiness with the left hemisphere dominance index has shown the significant links that characterize the potentially high level of technical skill of persons with the accented left hemisphere activity. The left hemisphere dominance influences significantly the body actions control during the passing $(\mathrm{r}=0.450 ; \mathrm{r}=0.501)$ and dribbling $(\mathrm{r}=-0.483$;

Table 1. Indicators of technical readiness of basketball players aged 12-13 with different cerebral asymmetry profile while exercising with the dominant hand.

\begin{tabular}{llll}
\hline Description of indicators & $\begin{array}{l}\text { The left hemisphere } \\
\text { dominance } \\
(\mathbf{n}=\mathbf{7})\end{array}$ & $\begin{array}{l}\text { The right hemisphere } \\
\text { dominance } \\
(\mathbf{n}=10)\end{array}$ & $\begin{array}{l}\text { Hemisphere } \\
\text { symmetry } \\
(\mathbf{n}=18)\end{array}$ \\
\hline Passes (number of times) & $38.43 \pm 2.85$ & $32.10 \pm 2.90^{*}$ & $35.22 \pm 1.88$ \\
Integrated Drill (s) & $25.14 \pm 0.40$ & $27.18 \pm 0.58$ & $25.82 \pm 0.61$ \\
Shots (number of times) & $3.86 \pm 0.24$ & $2.80 \pm 0.49^{*}$ & $3.11 \pm 0.28^{*}$ \\
Dribbling (s) & $4.04 \pm 0.05$ & $4.33 \pm 0.09^{*}$ & $4.13 \pm 0.04 \#$ \\
\hline
\end{tabular}

Note: ${ }^{*} p<0.05$ - in comparison with the indicators of the left hemisphere dominance; $\# p<0.05$ - Compared to the right hemisphere dominance. 
Table 2. Indicators of technical readiness of basketball players aged 12-13 with different cerebral asymmetry profile while exercising with the sub-dominant hand.

\begin{tabular}{llll}
\hline Description of indicators & $\begin{array}{l}\text { The left hemisphere } \\
\text { dominance } \\
(\mathbf{n}=\mathbf{7})\end{array}$ & $\begin{array}{l}\text { The right hemisphere } \\
\text { dominance } \\
(\mathbf{n}=10)\end{array}$ & $\begin{array}{l}\text { Hemisphere } \\
\text { symmetry } \\
(\mathbf{n}=18)\end{array}$ \\
\hline Passes (number of times) & $36.43 \pm 2.16$ & $26.20 \pm 2.15^{*}$ & $30.72 \pm 1.58 \# *$ \\
Integrated Drill (s) & $26.00 \pm 0.44$ & $27.47 \pm 0.81^{*}$ & $26.87 \pm 0.75$ \\
Shots (number of times) & $2.57 \pm 0.28$ & $1.90 \pm 0.43$ & $2.56 \pm 0.45$ \\
Dribbling (s) & $4.08 \pm 0.05$ & $4.49 \pm 0.11^{*}$ & $4.36 \pm 0.07^{*}$ \\
\hline
\end{tabular}

Note: ${ }^{*} p<0.05$ - in comparison with the indicators of the left hemisphere dominance; \#p<0.05 - Compared to the right hemisphere dominance.

Table 3. Correlation of technical readiness and the left hemisphere dominance of basketball players aged 12-13 ( $\mathrm{r}$ ).

\begin{tabular}{|c|c|c|}
\hline \multirow[t]{2}{*}{ Factors } & \multicolumn{2}{|c|}{ The Left-Hemisphere Dominance Index } \\
\hline & $\begin{array}{l}\text { Loose } \\
\text { Correlation }\end{array}$ & Average/Moderate Correlation \\
\hline Passes with dominant hand & & 0.450 \\
\hline Passes with sub-dominant hand & & 0.501 \\
\hline Integrated drill performance with dominant hand & -0.202 & \\
\hline Integrated drill performance with sub-dominant hand & -0.210 & \\
\hline Shot with dominant hand & & 0.361 \\
\hline Shot with sub-dominant hand & 0.020 & \\
\hline Dribbling with dominant hand & & -0.483 \\
\hline Dribbling with sub-dominant hand & & -0.335 \\
\hline
\end{tabular}

$\mathrm{r}=-0.335$ ) with dominant and sub-dominant hands, as well as the body actions control during shot with dominant hand $(\mathrm{r}=0.361)$ (Table 3).

\section{Discussion}

The results of the study showed that in the group of basketball players aged 12-13, motor asymmetry of the right-lateral type prevails. The maximum number of the right-sided motor lateralization of basketball players has been confirmed in the study of athletes of different qualifications $[5,7,16]$, according to which the athletes' left-handedness is considered to be a special selection feature. The results of our work demonstrated the diverse nature of the interhemispheric asymmetry of basketball players aged 12-13. It was found out that half of the group had no pronounced cerebral hemispheres asymmetry, the left hemisphere dominance occurred in 7 persons and the right hemisphere dominance occurred in 10 . The study on professional basketball players has been confirmed by our research [7], where almost $50 \%$ of athletes had interhemispheric correlation. The possibilities for speed increasing, passing accuracy and dribbling (with dominant and sub-dominant hands) in the athletes aged 12-13 with the left hemisphere dominance were defined. It was confirmed at the moderate and significant correlation levels. In highly skilled basketball players, the predominance of the left hemisphere asymmetry profile affects the coordination abilities, which is reflected in the passing accuracy and dribbling [11]. Among basketball players aged 12-13 with right lateralization and hemispheres symmetry, the motor asymmetry was recorded. But for most athletes, the ambidextrous process forming of passing and dribbling has been peculiar. The ambidextrous character of dribbling is manifested in basketball players with the left hemisphere dominance. The influence of basketball playing on the body movements bimanual character was demonstrated by basketball players aged 15 [10]. Studies on elite [17] and semi-professional basketball players [18] showed an increase of the game rate at a high level of competition, passing and dribbling with both hands. At the same time, the data that we obtained as a result of amateurs' playing aged 18-20 somewhat disagree with higher speed evidence while dribbling with dominant hand [20].

In the process of athletic activity, the interhemispheric asymmetry degree varies and depends on the type of motor action: when performing some actions, the asymmetry increases, while performing others - it is smoothed out [11]. In athletes aged 12-13, active smoothing of hands asymmetry during passes performing and dribbling occurs only in the case of the left hemisphere dominance.

However, asymmetry intensification during shots was observed in cases with functional activity of the left hemisphere. At the same time, the shots accuracy with 
dominant hand of basketball players with the left-sided lateral type was significantly different from other profiles.

We can draw a parallel with semi-professional basketball players' results, where the higher dominant hand accuracy has been revealed [5]. Taking into consideration the fact, that motor asymmetry is presented without determining the lateralization direction, we cannot compare the data with the results of amateurs aged 18-20. where the higher shots accuracy of left-handed athletes was found out [20].

\section{Conclusion}

The diverse nature of the interhemispheric asymmetry in basketball players aged 12-13, which affects technical readiness has been defined. Athletes with the left hemisphere dominance showed a higher level of readiness, compared with other groups under study. Approximately close were the young basketball players' indicators with hemispheres symmetry. The lowest level of technical readiness was recorded in basketball players with the right hemisphere dominance. It was found out that at the age of 12-13, the bimanual character of body movements in young basketball players with the left hemisphere dominance is being formed more actively. Significant rate improvement in passes, dribbling with both hands and the shot accuracy with dominant hand are directly linked with the left hemisphere dominance.

The pass indicators with a dominant hand as compared to subdominant one was higher in young basketball players with the left hemisphere dominance as well as with hemispheres symmetry. The higher indicators of shot accuracy with dominant hand as compared to subdominant in basketball players with the left hemisphere dominance and higher dribbling indicators in basketball players with hemisphere symmetry were found out. However, no indicators difference during the integrated drill performance with dominant and sub-dominant hands was established.

\section{Acknowledgement}

The research was carried out at the expense of the authors within the framework of the research project "Theoretical and Methodical Principles of Mobilization Readiness of Athletes of Various Qualifications" (state registration number 0116u003858). We thank the Basketball Club "Cherkasky Mavpy" for the participation in the study and testing organization.

\section{Conflict of interests}

The authors declare that there is no conflict of interests.

\section{References}

1. TommasiL.Mechanismsandfunctionsofbrainandbehavioural asymmetries. Phil. Trans. R. Soc. B. 2008; 364:855-859. https://doi.org/10.1098/rstb.2008.0293.

2. Peña-Melian A. Development of human brain. Human Evolution. 2000; 15, 99-112. https://doi.org/10.1007/BF02436238

3. Corballis M. Left Brain, Right Brain: Facts and Fantasies. PLoS Biology. 2014; 12(1):e1001767. https://doi.org/10.1371/journal.pbio.1001767

4. Corballis M. The evolution and genetics of cerebral asymmetry. Phil. Trans. R. Soc. B. 2009; 364:867-879. https://doi.org/10.1098/rstb.2008.0232

5. Ignat'yeva L, Maydokina L. Diagnostics of the interhemispherical asymmetry of the game-athletes. Modern science and education problems. 2016; 4: 45-52. (in Russian)

6. Anguera $M$, Camerino $O$, Castañer $M$, Sánchez-Algarra $\mathrm{P}$, Onwuegbuzie A. The Specificity of Observational Studies in Physical Activity and Sports Sciences: Moving Forward in Mixed Methods Research and Proposals for Achieving Quantitative and Qualitative Symmetry. Frontiers in Psychology. 2017; 8. https://doi.org/10.3389/fpsyg.2017.02196

7. Aganyants Ye, Berdichevskaya Ye, Gronskaya A, Perminova T, Ognerubova L. Functional asymmetries in sport: place, role and perspectives. Theory and practice of the physical culture. 2004; 8:22-24. (in Russian)

8. Vaisman A, Guiloff R, Rojas J, Delgado I, Figueroa D, Calvo R. Lower Limb Symmetry: Comparison of Muscular Power Between Dominant and Nondominant Legs in Healthy Young Adults Associated With Single-Leg-Dominant Sports. Orthopaedic Journal of Sports Medicine. 2017; 5(12):2325967117744240. https://doi.org/10.1177/2325967117744240

9. Guilherme J, Garganta J, Graça A, Seabra A. Effects of technical training in functional asymmetry of lower limbs in young soccerplayers. Revista Brasileirade Cineantropometria \& Desempenho Humano. 2015; 17(2):125-135. https://doi.org/10.5007/1980-0037.2015v17n2p125

10. Čvorović A. The Influence of Basketball on the Asymmetry in the Use of Limbs. Montenegrin Journal of Sports Science and Medicine. 2012; 1(1):15-19.

11. Khudik S, Chikurov A, Voynich A, Radayeva S. Functional asymmetry as a biological phenomenon associated with athletic performance. Bulletin of Tomsk State University. 2017; 421:193-202. https://doi.org/10.17223/15617793/421/29. (in Russian)

12.Korobeynikov G, Korobeinikova L. Functional Brain Asymmetry and Cognitive Functions in Elite Wrestlers. International Journal of Wrestling Science. 2014; 4(1):26-34. https://doi.org/10.1080/21615667.2014.10878997

13. WolfS, BrölzE, Keune PM, Wesa B, Hautzinger M, Birbaumer $\mathrm{N}$, Strehl U. Motor skill failure or flow-experience? Functional brain asymmetry and brain connectivity in elite and amateur table tennis players. Biological Psychology. 2015; 105:95-105. https://doi.org/10.1016/j.biopsycho.2015.01.007

14. Moskvin V, Moskvina N. Individual differences in the functional asymmetry in sport. Science in the olympic sport. 2015; 2:58-62. (in Russian)

15.Frolova L, Timofeyev A, Kelep A. The peculiarities of the nervous system properties of the junior volleyball players with different head brain hemispheres dominance manifestation. In: Materials of the XI International scientific and practical Internet-conference. Humanitarian space of science: experience and prospects, 2017 May 17; PereyaslavKhmelnytsky; 2017. P. 142-146. (in Ukrainian)

16.Kuchin R, Aksarin I. The study of the functional asymmetry profile of the junior basketball players aged 10 to 12 years. Yugorsky state university messenger. 2015; 1(36):79-82. https://doi.org/10.17816/byusu201511179-82. (in Russian) 
17.Stöckel T, Weigelt M. Plasticity of human handedness: Decreased one-hand bias and inter-manual performance asymmetry in expert basketball players. Journal of Sports Sciences. 2012; 30(10):1037-1045. https://doi.org/10.1080/02640414.2012.685087

18.Stöckel T, Vater Chr. Hand preference patterns in expert basketball players: Interrelations between basketball-specific and everyday life behavior. Human Movement Science. 2014; 38:143-151. https://doi.org/10.1016/j.humov.2014.09.002
19.Tousi M, Emami T, Hoseini S. The Effect of Initial Practice with Dominant and Non-Dominant Hand on Acquisition, Retention and Transfer of A Complex Motor Task. Biosci Biotech Res Asia. 2017; 14(3):1067-1074. https://doi.org/10.13005/bbra/2543

20.Porozovs J, Praulīte G, Spunde A, Perepjolkina V, Voita D, Vaļēviča E, Kauliņa A. Peculiarities of psychophysiological function of sportsmen with different dominance of brain hemispheres. Lase journal of sport science. 2011; 2:12-24.

\section{Information about the authors:}

Frolova L.S.; (Corresponding author); http://orcid.org/ 0000-0003-0763-7509; I-f2014@vu.cdu.edu.ua; The Bohdan Khmelnytsky National University of Cherkasy, Ukraine.; 81, Shevchenko Blvd., 18031, Cherkasy, Ukraine.

Petrenko Yu.A.; http://orcid.org/ 0000-0002-6348-2110; Petrenko62@gmail.com; The Bohdan Khmelnytsky National University of Cherkasy, Ukraine.; 81, Shevchenko Blvd., 18031, Cherkasy, Ukraine.

Tymofeev A.A.; http://orcid.org/ 0000-0002-9851-0257; 13tim@i.ua; The Bohdan Khmelnytsky National University of Cherkasy, Ukraine.; 81, Shevchenko Blvd., 18031, Cherkasy, Ukraine.

Gunko P.M.; http://orcid.org/0000-0002-0609-8550; gunkopeter@bigmir.net; The Bohdan Khmelnytsky National University of Cherkasy, Ukraine.; 81, Shevchenko Blvd., 18031, Cherkasy, Ukraine.

Okhrimenko O.V.; http://orcid.org/0000-0002-6609-3073; okhrimprepodsa@ukr.net; The Bohdan Khmelnytsky National University of Cherkasy, Ukraine.; 81, Shevchenko Blvd., 18031, Cherkasy, Ukraine.

Khaliavka R.M.; http://orcid.org/0000-0003-0591-82941; Rojahroma@gmail.com; The Bohdan Khmelnytsky National University of Cherkasy, Ukraine.; 81, Shevchenko Blvd., 18031, Cherkasy, Ukraine.

Cite this article as:

Frolova LS, Petrenko Yu.O, Tymofeev AA, Gunko PM, Okhrimenko OV, Khaliavka RM. Technical readiness of young basketball players with different profile of functional asymmetry. Pedagogics, psychology, medical-biological problems of physical training and sports, 2019;23(3):132-137. https://doi.org/10.15561/18189172.2019.0304

This is an Open Access article distributed under the terms of the Creative Commons Attribution License, which permits unrestricted use, distribution, and reproduction in any medium, provided the original work is properly cited (http://creativecommons.org/licenses/by/4.0/deed.en).

Received: 16.03 .2019

Accepted: 25.04.2019; Published: 29.06.2019 